\title{
Hemodynamic testing using three-dimensional printing and computational fluid dynamics preoperatively may provide more information in mitral repair than traditional image dataset
}

\author{
Hao Wang ${ }^{1}$, Hongning Song ${ }^{1}$, Yuanting Yang ${ }^{1}$, Zhiyong $\mathrm{Wu}^{2}$, Rui $\mathrm{Hu}^{2}$, Jinling Chen ${ }^{1}$, Juan Guo ${ }^{1}$, \\ Yijia Wang ${ }^{1}$, Dan Jia ${ }^{1}$, Sheng Cao ${ }^{1}$, Qing Zhou ${ }^{1}$, Ruiqiang Guo ${ }^{1}$ \\ ${ }^{1}$ Department of Ultrasound Imaging, Renmin Hospital of Wuhan University, Wuhan, China; ${ }^{2}$ Department of Cardiovascular Surgery, Renmin \\ Hospital of Wuhan University, Wuhan, China \\ Contributions: (I) Conception and design: H Wang, H Song; (II) Administrative support: Q Zhou, R Guo; (III) Provision of study materials or \\ patients: Z Wu, R Hu, J Chen; (IV) Collection and assembly of data: J Guo, Y Wang; (V) Data analysis and interpretation: D Jia, S Cao; (VI) \\ Manuscript writing: All authors; (VII) Final approval of manuscript: All authors. \\ Correspondence to: Qing Zhou; Ruiqiang Guo. Department of Ultrasound Imaging, Renmin Hospital of Wuhan University, Wuhan 430060, China. \\ Email: qingzhou@whu.edu.cn; ruiqiangwhrm@hotmail.com.
}

Background: Mitral valve repair (MVR) has been considered superior to mitral replacement for degenerative $M V$ disease and even rheumatic diseases. However, the repair rate varies widely depending on the medical center and the surgeons' experience. The aim of our study was to apply three-dimensional printing (3DP) and computational fluid dynamics (CFD) in surgical simulation to provide reference for surgical decision-making, especially for inexperienced surgeons.

Methods: Our study included retrospective and prospective cohorts. We first enrolled the retrospective cohort of 35 patients who were prepared to have MVR, aiming at exploring the feasibility of surgical simulation using 3DP and CFD. Three-dimensional transesophageal echocardiography (3D-TEE) and computed tomography angiography (CTA) were performed for all patients, and imaging data were fused to construct a 3D digital model. Next, the model was used to make the 3DP dynamic model and for CFD analysis. Mitral repair was simulated in both the 3DP dynamic model and CFD to predict surgical outcomes (grade of regurgitation and vena contracta width) and possible complications (systolic anterior motion, left ventricular outflow tract obstruction). Second, a prospective cohort of 20 patients was studied with 10 patients placed in a 3DP-guided group and 10 in an image-guided group. Rate of transformation to mitral replacement, surgery time, surgical outcomes, and surgical complications were compared between groups.

Results: Of the 35 patients retrospectively enrolled, 14 underwent MVR and 21 were transferred to mitral replacement. Surgical simulation for the 14 MVR patients showed high consistency with in vivo results. The result of surgical simulation for the 21 patients transferred to mitral replacement showed that 7 might have benefited from MVR. In the prospective cohort, the rate of transformation to mitral replacement and surgery time in the 3DP-guided group were significantly lower than those in the image-guided group.

Conclusions: 3DP and CFD models based on image data can be used for in vitro surgical simulation. These emerging technologies are now changing traditional models of diagnosis and treatment, and the role of imaging data will no longer be limited to diagnosis but will contribute more to assisting surgeons in choosing treatment strategies.

Keywords: Three-dimensional printing (3DP); computational fluid dynamics (CFD); mitral repair; surgery simulation

Submitted Dec 15, 2020. Accepted for publication Feb 04, 2021.

doi: $10.21037 /$ atm-20-7960

View this article at: http://dx.doi.org/10.21037/atm-20-7960 


\section{Introduction}

Mitral valve repair (MVR), including wedge resection of the leaflet, mitral annuloplasty, and mitral clip, has been recommended as the preferred surgical treatment of primary mitral regurgitation (MR) in recent years $(1,2)$, because it better protects cardiac function compared with MV replacement. However, surgeons, especially younger, less-experienced ones, are often reluctant to repair the MV because the outcome of the operation is considered unpredictable $(3,4)$. A second operation may be needed if $M V$ function does not improve significantly after repair. Furthermore, possible complications, including perivalvular leakage, systolic anterior motion (SAM) of the anterior MV leaflet (AML), and left ventricular outlet (LVOT) obstruction $(5,6)$ after MVR are also concerns for surgeons before surgery. About $5-10 \%$ of patients who undergo MVR for myxomatous MV disease develop LVOT obstruction caused by SAM (7-9). This can be lifethreatening when it occurs because of the rapid change in hemodynamics.

In recent years, various methods for simulating surgery in vitro have been more widely applied for cardiovascular diseases, including three-dimensional printing (3DP) $(10,11)$ and computational fluid dynamics (CFD) (12). Traditional medical image datasets that have customarily been used in cardiac dimension assessment and diagnosis of cardiovascular disease are now seeing novel application in surgical simulation and surgical decision-making. In this study, we used multimodality image data, including 3D transesophageal echocardiography (3D-TEE) and computed tomography angiography (CTA), and attempted to simulate MVR in vitro using 3DP and CFD for patients with primary MR. The outcome of our surgical simulation might provide references for cardiovascular surgeons, thereby assisting them in choosing the optimal surgical strategy. We present the following article in accordance with the MDAR reporting checklist (available at http://dx.doi.org/10.21037/atm-20-7960).

\section{Methods}

\section{Retrospective cohort}

\section{Multimodality image data set}

From September 2016 to November 2018 , we retrospectively enrolled 35 patients who had MR and were prepared to have MVR at Renmin Hospital of Wuhan University (15 male patients, 20 female patients). The inclusion criteria were the following: moderate or more severe MR; anatomy of the MV suitable for MVR (Carpentier type II, part of Carpentier type I with clefts or isolated damage to the valve from previous infective endocarditis); good 3D-TEE image quality that clearly displayed the mitral leaflets; no history of allergy to CT contrast agents. Of note, for patients with mitral annular calcification, the severity of the calcification was qualitatively determined as mild (limited increased echodensity of aortic annulus), moderate (extensive echodensity involving $>50 \%$ of ring circumference, but with preservation of leaflet mobility), and severe (extensive echodensity involving entire circumference of aortic ring, and with limitation of leaflet excursion) (13). The exclusion criteria were the following: severe cardiac dysfunction [left ventricular (LV) ejection fraction $(\mathrm{EF})<30 \%$ ]; severe renal dysfunction; severe calcification of the annulus; severe calcification and fibrosis of the MV leaflets. We excluded the patients with an EF $<30 \%$ according to the 2017 American College of Cardiology/American Heart Association (AHA/ACC) Focused Update of the 2014 AHA/ACC Guideline for the Management of Patients with Valvular Heart Disease (14), which indicates that patients with an $\mathrm{EF}<30 \%$ are weakly recommended (Class: IIb) for MV surgery. The study was conducted in accordance with the Declaration of Helsinki (as revised in 2013). The study was approved by Clinical Research Ethics Committee of Renmin Hospital of Wuhan University (No. WDRY2018-K032) and informed consent was taken from all individual.

CTA and 3D-TEE were performed in all patients before surgery with a 256-row Revolution CT scanner, an ADW 4.6 workstation, and a Vivid iq (GE Healthcare). The scanning range of CTA was about $5 \mathrm{~cm}$ from the level of the tracheal bifurcation to the diaphragm. A prospective electrocardiogram (ECG)-gated breath hold scan was performed using a contrast agent tracking technique. The region of interest (ROI) was placed at the ostium of the coronary artery for monitoring. When the CT value in the ROI exceeded $180 \mathrm{HU}$, the scan was triggered manually. The scanning parameters were as follows: tube voltage 100$120 \mathrm{kV}$, tube current $300-650 \mathrm{~mA}$, detector configuration 256 rows $\times 0.625 \mathrm{~mm}$, ball tube speed $0.28 \mathrm{~s} / \mathrm{r}$, and scanning layer thickness $0.625 \mathrm{~mm}$. The original image data were stored in digital imaging and communication in medicine (DICOM) format and transmitted to the GE ADW 4.6 workstation.

A 3D-TEE volume probe (6vt-d) was used to obtain the 3D-TEE data with a frequency of 3.0-8.0 Mhz. A clear $2 \mathrm{D}$ image of the $\mathrm{MV}$ was obtained with the probe at the 

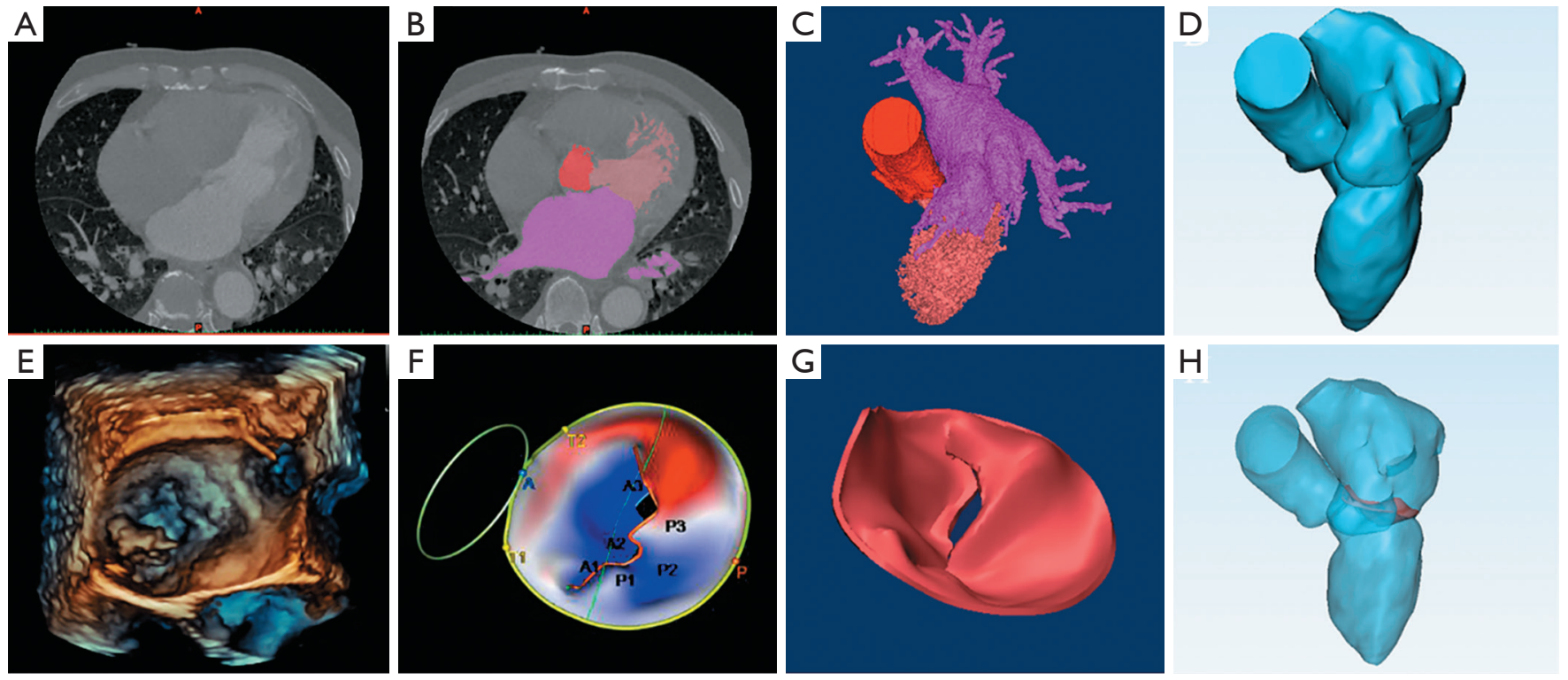

Figure 1 Three-dimensional digital model of the left heart based on a multimodality image data set. (A,B,C,D) CTA DICOM images were postprocessed to obtain a digital left heart cavity. (E,F,G,H) Mitral valve model based on fusion of 3D-TEE images to view the whole left heart system. 3D-TEE, three-dimensional transesophageal echocardiography; CTA, computed tomography angiography; DICOM, digital imaging and communication in medicine.

mid-esophagus level, and the valve was integrated into the sampling frame. The sampling frame rate was 8-12 frames/s. The total gain and probe angle were adjusted appropriately before entering 4D mode. Finally, the full volume images of 5 consecutive cardiac cycles were stored and imported into the EchoPac workstation (GE Healthcare) for postprocessing analysis in DICOM format.

\section{D digital model}

Both the CTA and 3D-TEE DICOM images in 35\% R-R interval were derived and imported into postprocessing software, including Mimics 19.0 and 3-matic 11.0 (Materialise, Leuven, Belgium). The CTA image data were segmented to create the digital model of the left heart cavity while the 3D-TEE data were postprocessed to exactly recreate the MV structure. Threshold segmentation is mainly used in data post-processing. The range of threshold is set at $180-850 \mathrm{HU}$ in the CTA image, and the $3 \mathrm{D}$ mask (mask) of the left heart cavity can be obtained using the CT heart function in the software. The range of threshold was set at 70-240 HU in the 3D-TEE image to exactly recreate the MV structure. Points on the mitral annulus with small movement were marked as registration points, and the two different modes of cardiac imaging were fused. Finally, a $3 \mathrm{D}$ digital model of the left heart system, including left atrium (LA), LV, aorta (Ao) and MV, was obtained using the fusion method (Figure 1). It was saved in STL format after smoothing and noise reduction. Mitral annular calcification was segmented by raising the value of the threshold and then saved separately in STL. After being printed, the calcified section was combined with the silicone valve model for integration into a whole model.

\section{DP dynamic model}

The 3DP dynamic model had two main components: a flexible 3DP model and a mock circulatory system (MCS). Unlike traditional 3D printing, which usually uses rigid materials such as polylactic acid and acrylonitrile butadiene styrene, we made a flexible 3DP model using our specific mold modeling method. First, the left heart system model was further processed to create a mold. The mold was then 3D-printed using soluble material (polyvinyl alcohol, PVA). The printing temperature was $185^{\circ} \mathrm{C}$ with the heating bed at $60{ }^{\circ} \mathrm{C}$. The thickness of each layer was $0.1 \mathrm{~mm}$. A custommade special silicone (mixture of silicone, starch, cellulose, and hardener in specific proportions) was stirred evenly and degassed in a vacuum defoamer for approximately 10 minutes. The silicone mixture was then poured into the $3 \mathrm{D}$ mold and allowed to solidify for approximately 6 hours. After that, the model was placed in water to remove the shell, and the flexible 

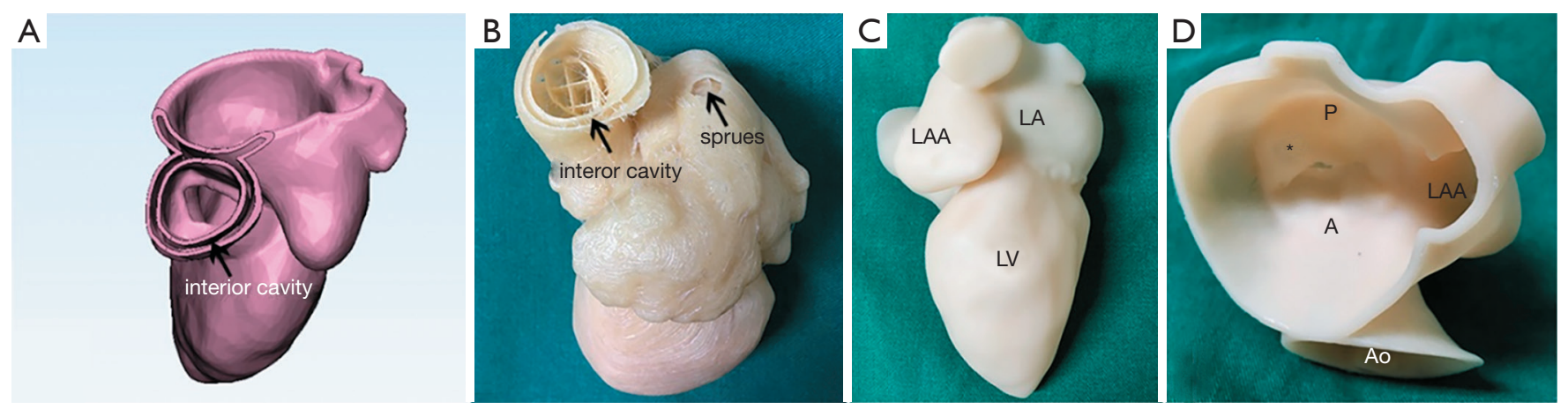

Figure 2 Workflow of creating the flexible 3D-printed model. (A) Hollow mold of heart model; (B) hollow mold is 3D-printed using soluble material-PVA; (C,D) final flexible 3D model made of silicone. LA, left atrium; LV, left ventricle; LAA, left atrial appendage; Ao, aorta. *, lesion area.
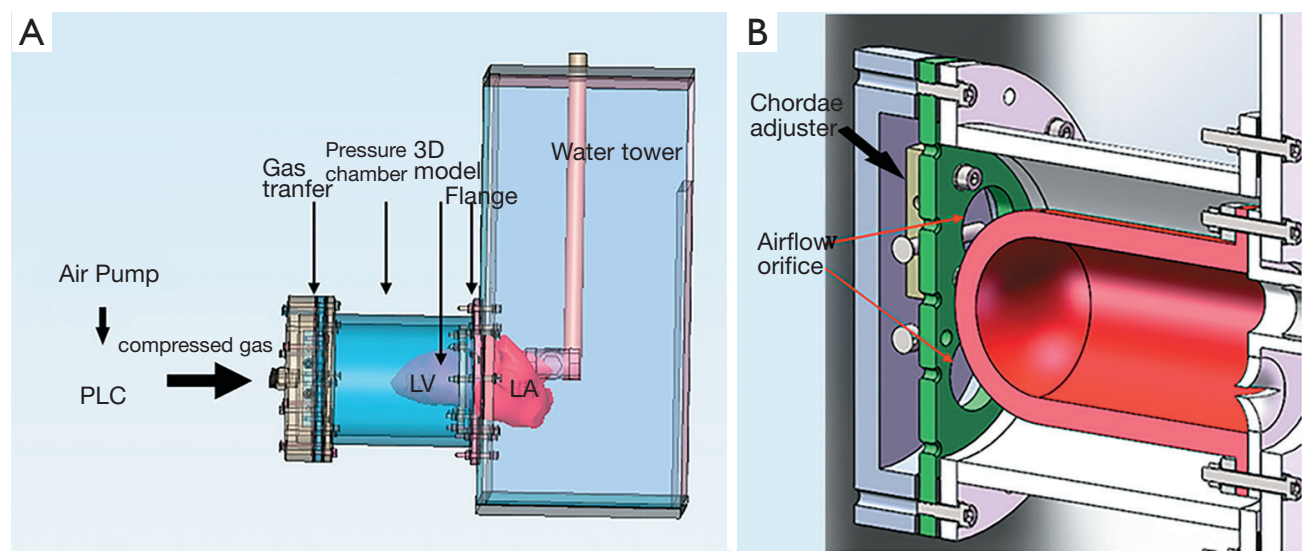

Figure 3 MCS. (A) General overview of the MCS. Compressed gas was generated from air pump and regulated by PLC. The 3DP heart model in a pressure chamber contracts and relaxes with compressed gas moving in and out. A pressure-elevating water tower is used to simulate afterload in systole. (B) Cutaway view showing gas transfer including the airflow orifice (red arrow) and chordae adjuster (black arrow). PLC, programmable logic controller; MCS, mock circulatory system; 3DP, three-dimensional printing.

3D model was completed (Figure 2). The flexible 3D model had a tensile modulus of $0.31 \mathrm{mPa}$, which is similar to that of cardiac muscles and the MV.

The MCS was powered by an air compressor (Figure 3), and a programmable logic controller (PLC) was used to control the driver. The compressed gas generated by the air pump was transferred to a pressure cell surrounding the flexible 3D model to make it contract and relax rhythmically. A pressure-elevating water tower was used as the systematic compliance component to simulate afterload in systole. The MCS generated a maximum systolic pressure of $107 \mathrm{mmHg}$, which is near physiological conditions. To simulate in vivo blood flow resistance, solutions with a viscosity similar to blood ( 3.5-4.5 mPa/s) were also needed. Water, glycerol, dextran, and surfactants were mixed as the substitute. Nylon scattering particles with a diameter of $5 \mu \mathrm{m}$ were also added for better echographic imaging. After being combined with the MCS, the flexible 3DP model of the MV could open and close in vitro as it does in vivo.

\section{CFD}

Comsol Multiphysics 5.5 (COMSOL Inc., Stockholm, Sweden) was used to reconstruct the mesh of the left heart system (Figure 4). Before being imported into Comsol Multiphysics, the mesh quality of the left heart model was simply refined using the remesh function in 3-matic. "Boundary partitioning" and "Repair tolerance" were also adjusted appropriately after the mesh was imported into COMSOL, 
A

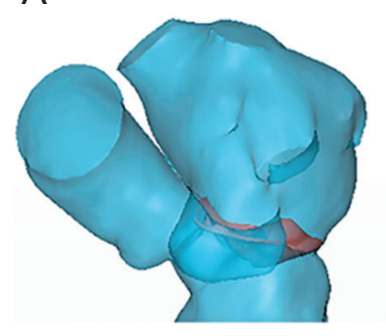

C

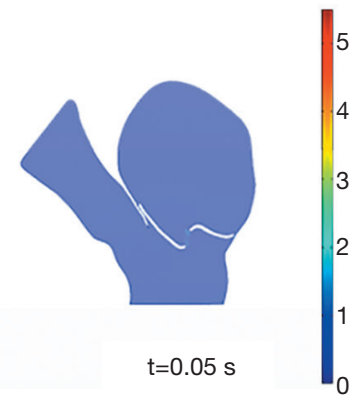

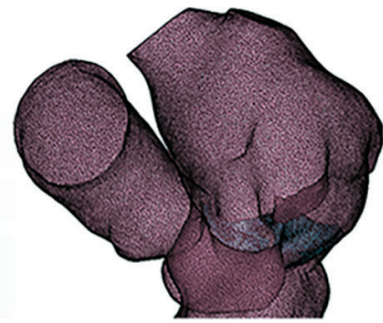

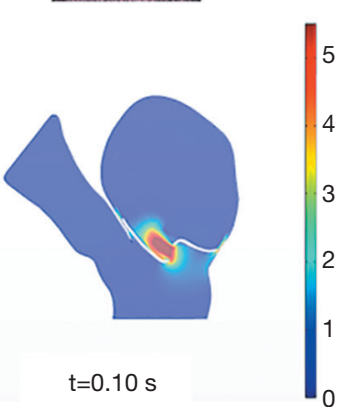

B
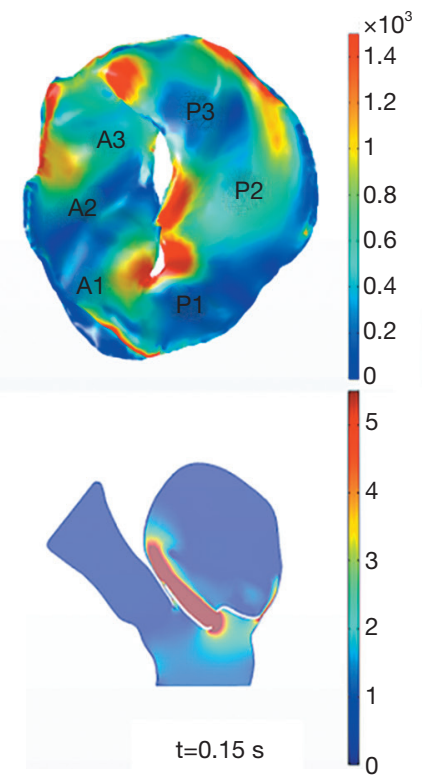
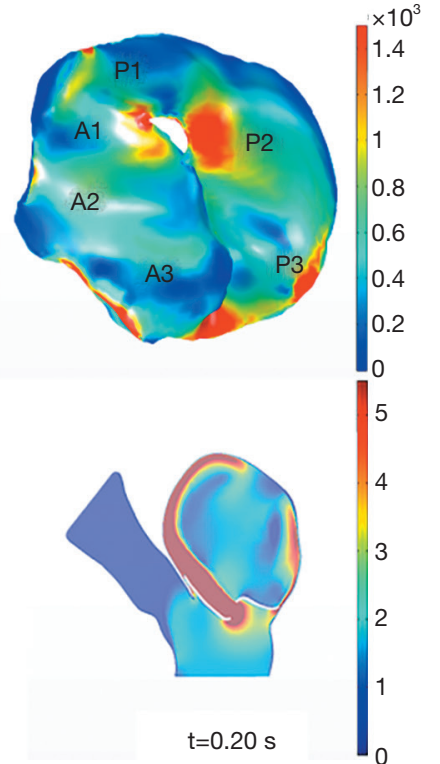

Figure 4 CFD simulation of mitral regurgitation. (A) Mesh of the left heart system. (B) Stress analysis of prolapsed P3 mitral valve. Maximal stress mainly distributed at the boundary of P2 and P3, as well as the mitral annulus adjacent to P3. (C) The flow stream of regurgitation in systole. Consistent with in vivo, there was a severe eccentric regurgitation stream flowing in the direction of the anterior mitral valve, reaching the top of the left atrium at 0.20 seconds. CFD, computational fluid dynamics.

to further refine its quality. In material science, it is assumed that the blood is an incompressible Newtonian fluid: blood viscosity $\mu=0.0035 \mathrm{~kg} / \mathrm{ms}$; density $\rho=1,050 \mathrm{~kg} / \mathrm{m}^{3}$. A fluidsolid interaction (FSI) multiphysics interface was used to model the physics which are involved when blood and heart tissue affect each other. It was assumed that heart tissue is rigid, impermeable, and wall sliding. Heart rate was assumed to be 75 beats $/ \mathrm{min}$ and the cardiac cycle was $\mathrm{t}=0.8 \mathrm{~s}$. Blood flow in the left heart conforms to the following continuity equation of mass conservation and 3D unsteady Navier-Stokes equation of momentum conservation:

$$
\frac{\partial u}{\partial x}+\frac{\partial v}{\partial y}+\frac{\partial w}{\partial z}=0
$$

$\mathrm{u}, \mathrm{v}$, and $\mathrm{w}$ represent velocity components in the $\mathrm{X}, \mathrm{Y}$, and $\mathrm{Z}$ directions respectively.

\section{Surgical simulation using 3DP model and CFD}

Surgical simulation was performed using both the dynamic 3DP model and CFD. For the dynamic 3DP model, two experienced cardiothoracic surgeons were invited to perform MVR with the same-sized annuloplasty ring as used in patients; meanwhile for CFD simulation, different digital models of annuloplasty rings with diameters from 26 to $38 \mathrm{~mm}$ were designed using 3-matic. The simulation of MVR was accomplished using Meshmixer software (Figure 5).

The severity of MR was assessed qualitatively and quantitatively before and after the surgical simulation and compared with in vivo 3D-TEE data. The grade of MR from 1 to 4 was defined as mild, moderate, moderate to severe, and severe, respectively. In the quantitative assessment, vena contracta width (VCW) was measured both in vitro and in vivo.

\section{Prospective cohort}

A total of 20 patients who had MR and underwent MVR between December 2018 and September 2020 were prospectively studied. Patients were divided into a 3DPguided group and an image-guided group, and preoperative surgical simulations using the 3DP dynamic model and CFD were performed for patients in the $3 \mathrm{DP}$-guided group. The optimal surgical strategy was decided based on the results of the simulation. For the patients in imageguided group, surgical decision was based on traditional image analysis of the 3D-TEE and CTA images. Rate of transformation to mitral replacement, surgery time, surgical outcomes, and surgical complications were compared 

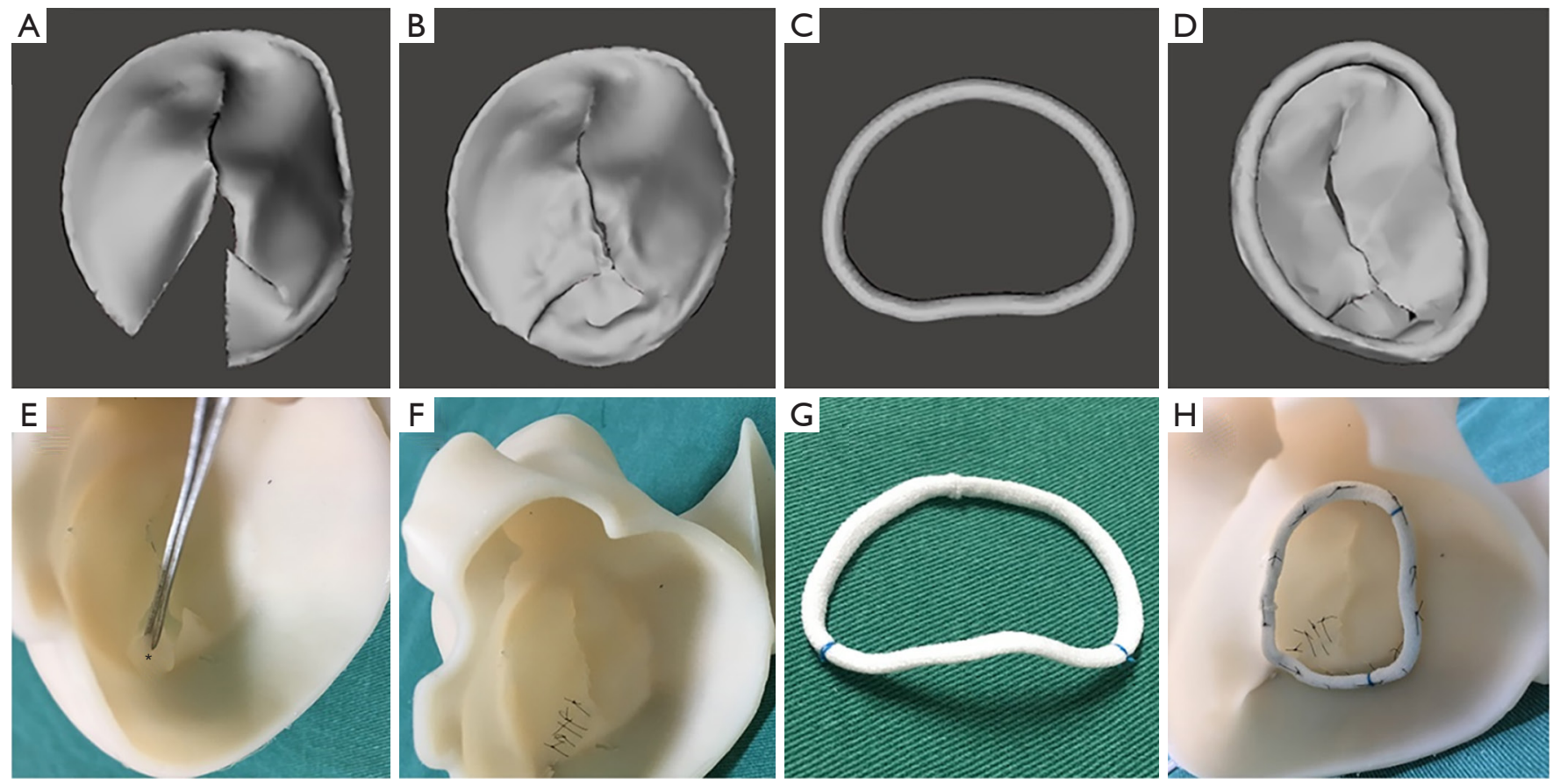

Figure 5 Surgical simulation using CFD (A,B,C,D) and three-dimensional model (E,F,G,H). (A,E) Resection of lesion area; (B,F) repaired leaflet; $(\mathrm{C}, \mathrm{G})$ annuloplasty ring; $(\mathrm{D}, \mathrm{H})$ annuloplasty ring tied in place. $\mathrm{CFD}$, computational fluid dynamics.

Table 1 Clinical characteristics of patients

\begin{tabular}{ll}
\hline Clinical characteristics & Values \\
\hline Mean age (years) & $51.8 \pm 13.4$ \\
Male & $15 / 35$ \\
Mitral disease & \\
Degenerative disease & $32 / 35$ \\
Valvular dehiscence & $2 / 35$ \\
Accessory mitral valve & $1 / 35$ \\
Severity & \\
Moderate & $2 / 35$ \\
Moderate to severe & $5 / 35$ \\
Severe & $28 / 35$ \\
Region & \\
Anterior leaflet & $5 / 35$ \\
Posterior leaflet & $26 / 35$ \\
Multi-segment involving both leaflets & $4 / 35$ \\
Procedures performed & \\
Repair & $14 / 35$ \\
Transferred to replacement & $21 / 35$ \\
\hline
\end{tabular}

between groups.

\section{Statistical analysis}

Continuous and categorical variables are described respectively as the mean \pm standard deviation and percentages. For continuous variables, a paired $t$-test was used for paired data on the basis that differences between groups conformed to the laws of a normal distribution. A $\mathrm{P}$ value $<0.05$ (bilateral test) was considered to indicate a statistically significant difference.

\section{Results}

\section{Retrospective cohort}

\section{Comparison of surgical outcomes in vitro and in vivo}

The 35 patients included in our study (Table 1) comprised 2 patients with moderate MR, 5 patients with moderateto-severe MR and 28 patients with severe MR. Of them, 32 patients suffered from MV prolapse attributed to degenerative disease, including 26 cases of posterior $\mathrm{MV}$ leaflet (PML) prolapse, 2 cases of AML prolapse and 4 cases of multi-segment prolapse involving both the AML and 
PML. In total there were 14 cases of successful MVR and 21 cases of transfer to MV replacement.

In all patients, the grade of MR and the VCW measured in vitro and in vivo before surgery were highly consistent (Tables 2,3, Figure 6). With the 3DP model, 3 patients were assessed as moderate MR, 4 as moderate-to-severe MR, and 28 with severe MR. Only one patient was assessed as moderate $\mathrm{MR}$ in vitro but had moderate-to-severe $\mathrm{MR}$ in vivo, and one patient was assessed as moderate-to-severe by CFD but was severe in vivo (Table 2).

Surgical simulations were successfully done in vitro (both dynamic 3DP model and CFD) for all 14 patients who had MVR. The grade of MR and the VCW showed a significant decline after the surgical simulation (Figure 7). The difference between the data obtained in vitro and in vivo was not statistically significant $(\mathrm{P}<0.05$, Table 3, Figure 6).

\section{Simulation of patients transferred to mitral replacement Patients with severely prolapsed MV}

There were 21 patients who were transferred to mitral replacement. Of them, 11 had a severely prolapsed PML and excessive removal contributed to adverse outcomes after surgery and even a second operation. We simulated the MV repair procedure in these patients using the 3DP model and CFD, and found that 5 of them tolerated surgery well with only minor MR. The other 6 patients had mild or more MR after surgery. Details of the patients before and after surgery are summarized in Table 4.

\section{Special cases}

Of the 21 patients who were transferred to mitral

Table 2 Grade of regurgitation measured using 3DP model, CFD and in vivo before surgery

\begin{tabular}{lccc}
\hline \multirow{2}{*}{ Methods } & \multicolumn{3}{c}{ Severity } \\
\cline { 2 - 4 } & Moderate & Moderate to severe & Severe \\
\hline In vivo & 2 & 5 & 28 \\
3DP & 3 & 4 & 28 \\
CFD & 2 & 6 & 27 \\
\hline
\end{tabular}

replacement, there was one with Barlow disease (BD). The MV leaflets were redundant, with prolapse of $\mathrm{P} 2$ and P3. 3D-TEE showed billowing of both AML and PML, especially the P3 segment. Color Doppler showed severe MR originating from the PML. One challenge of repairing $\mathrm{BD}$ mitral valves is the development of postoperative SAM of the AML, which is often associated with a tall PML. As the height of the PML increases, the coaptation point gets closer to the base of the AML, and the length of the AML beyond the coaptation point (residual length) increases. Residual AML is free to move in response to the drag created by the jet flow, which can cause SAM and LVOT obstruction. We simulated the procedure with different PML lengths from 14.0 to $19.0 \mathrm{~mm}$ (with an $0.5 \mathrm{~mm}$ increase on each attempt). The residual length of the AML ranged from 2.8 to $5.4 \mathrm{~mm}$ (Table 5). The results show that SAM and LVOT obstruction occurred when the PML length reached $16.5 \mathrm{~mm}$, with a residual length of the AML at $4.2 \mathrm{~mm}$ (Figure 8). The pressure gradient at the LVOT reached $17.2 \mathrm{mmHg}$ after repair, but was only $6.8 \mathrm{mmHg}$ before surgery.

Another patient, a 62-year-old woman, had a small left heart cavity, which is also a risk factor of postoperative LVOT obstruction. Echocardiography showed that the LV endsystolic dimension was $41 \mathrm{~mm}$. Of note, the patient had suffered from hypertension for more than 10 years. The LA dimension was $36 \mathrm{~mm}$ (reference: $25-35 \mathrm{~mm}$ ) and the ascending aorta dimension was $37 \mathrm{~mm}$ (reference: $23-32 \mathrm{~mm}$ ). The interventricular septal (IVS) thickness was $14 \mathrm{~mm}$ (reference: 6-10 mm), which could increase the risk of LVOT obstruction after surgery. Firstly, we simulated MV repair in vitro without any intervention to the IVS. The results showed that pressure gradient at the LVOT reached $18.4 \mathrm{mmHg}$. We further attempted septal myectomy in the model (with $0.5 \mathrm{~mm}$ decrease of the IVS thickness on each attempt) and found an optimistic surgical outcome when the IVS thickness was less than $12.0 \mathrm{~mm}$ (Table 6, Figure 9). This suggested that conservative medical treatment (e.g., betablockers) or surgical intervention would be necessary to avoid adverse outcomes for this patient.

Table 3 Vena contracta width ( $\mathrm{mm}$ ) measured using 3DP model, CFD and in vivo before and after surgery

\begin{tabular}{lcccccc}
\hline Time & 3DP model & CFD & In vivo & $\mathrm{t}^{\mathrm{a}}$ & $\mathrm{P}^{\mathrm{a}}$ & $\mathrm{t}^{\mathrm{b}}$ \\
\hline Before surgery & $6.46 \pm 1.38$ & $6.55 \pm 1.04$ & $6.70 \pm 1.32$ & 1.67 & 0.12 & 1.06 \\
After surgery & $1.15 \pm 0.46$ & $1.21 \pm 0.45$ & $1.24 \pm 0.54$ & 1.03 & 0.32 & 0.31 \\
\hline
\end{tabular}

$\mathrm{t}^{\mathrm{a}}, \mathrm{P}^{\mathrm{a}}$ : comparation of 3DP model and in vivo; $\mathrm{t}^{\mathrm{b}}, \mathrm{P}^{\mathrm{b}}$ : comparation of $\mathrm{CFD}$ and in vivo. 

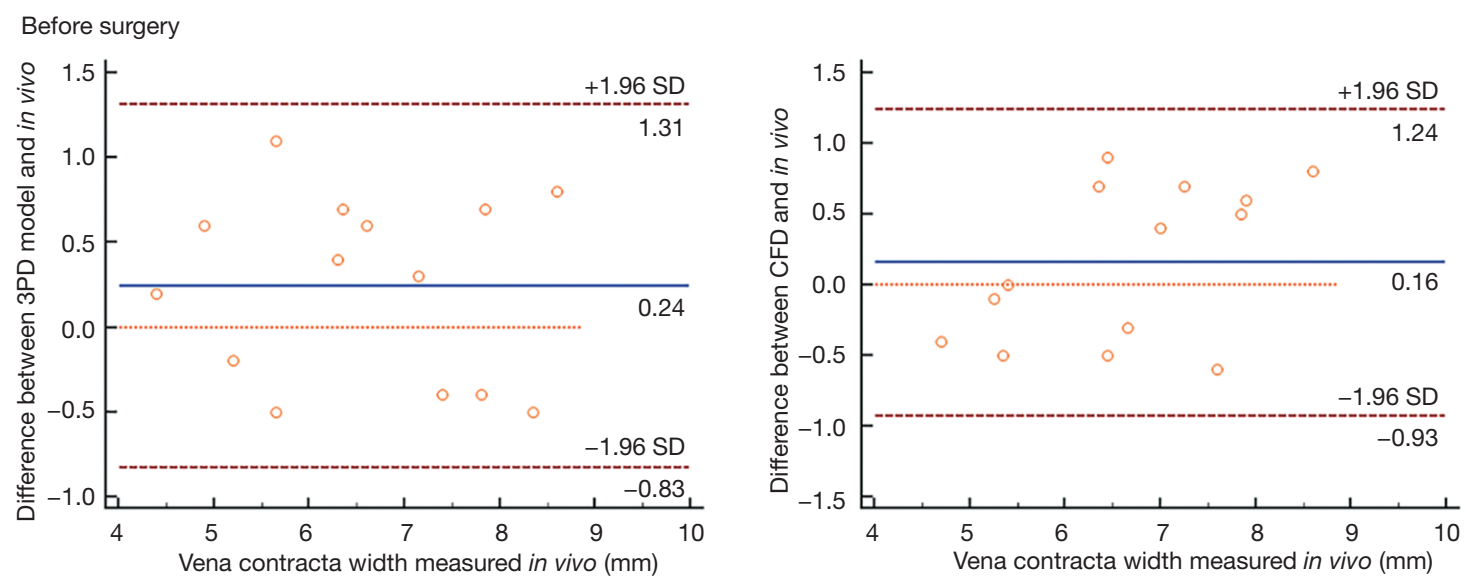

After surgery
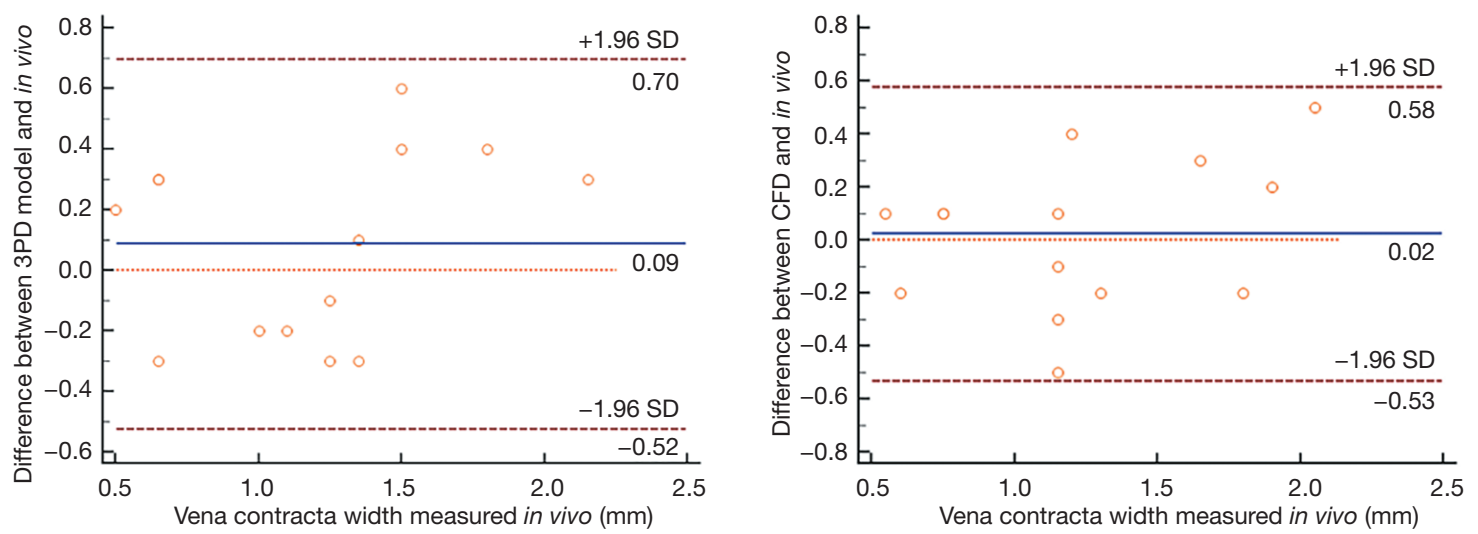

Figure 6 Bland-Altman plots of coherence before and after surgical simulations. The $\mathrm{x}$-axis is the mean VCW assessed in vivo, and the $\mathrm{y}$-axis is the difference in VCW between in vitro and in vivo. The dots are distributed evenly above and below the average line (blue line), which was very close to $\mathrm{y}=0$ (brown line). Therefore, we assumed that the in vitro data were consistent with the in vivo data. VCW, vena contracta width.

\section{Comparison of surgical simulation using the 3DP dynamic model and CFD}

Data obtained using the 3DP dynamic model and CFD was highly consistent. The difference in VCW between the 3DP model and CFD was not statistically significant $(\mathrm{P}<0.05)$. However, compared with $\mathrm{CFD}$, it took more time for the surgical simulation and hemodynamics testing in the 3DP model, with an average time of about 6 hours for 1 patient, compared with only 1 hour with CFD (Table 7).

\section{Prospective cohort}

Mean age, sex, and severity of MR in the 3DP-guided group and image-guided group were not statistically different. Mitral repair was done for 3 patients in the image-guided group and 6 patients in the 3DP-guided group. Although not statistically different, the rate of transfer to replacement was significantly lower in the 3DP-guided group (Table 8). Surgery time was also lower in the $3 \mathrm{DP}$-guided group. No complications occurred in either group.

\section{Discussion}

The 2017 AHA/ACC Guideline for the Management of Patients with Valvular Heart Disease (1) recommends MV repair in preference to MVR when surgical treatment is indicated for patients with chronic severe primary MR. Compared with MV replacement, postoperative anticoagulation is not required after MVR, which can reduce the occurrence of endocarditis and thromboembolic 

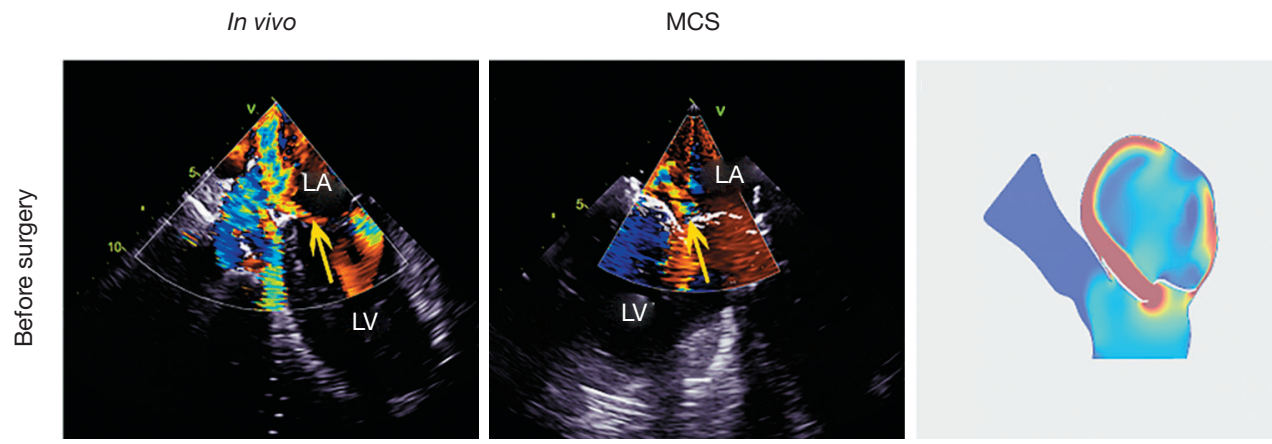

CFD
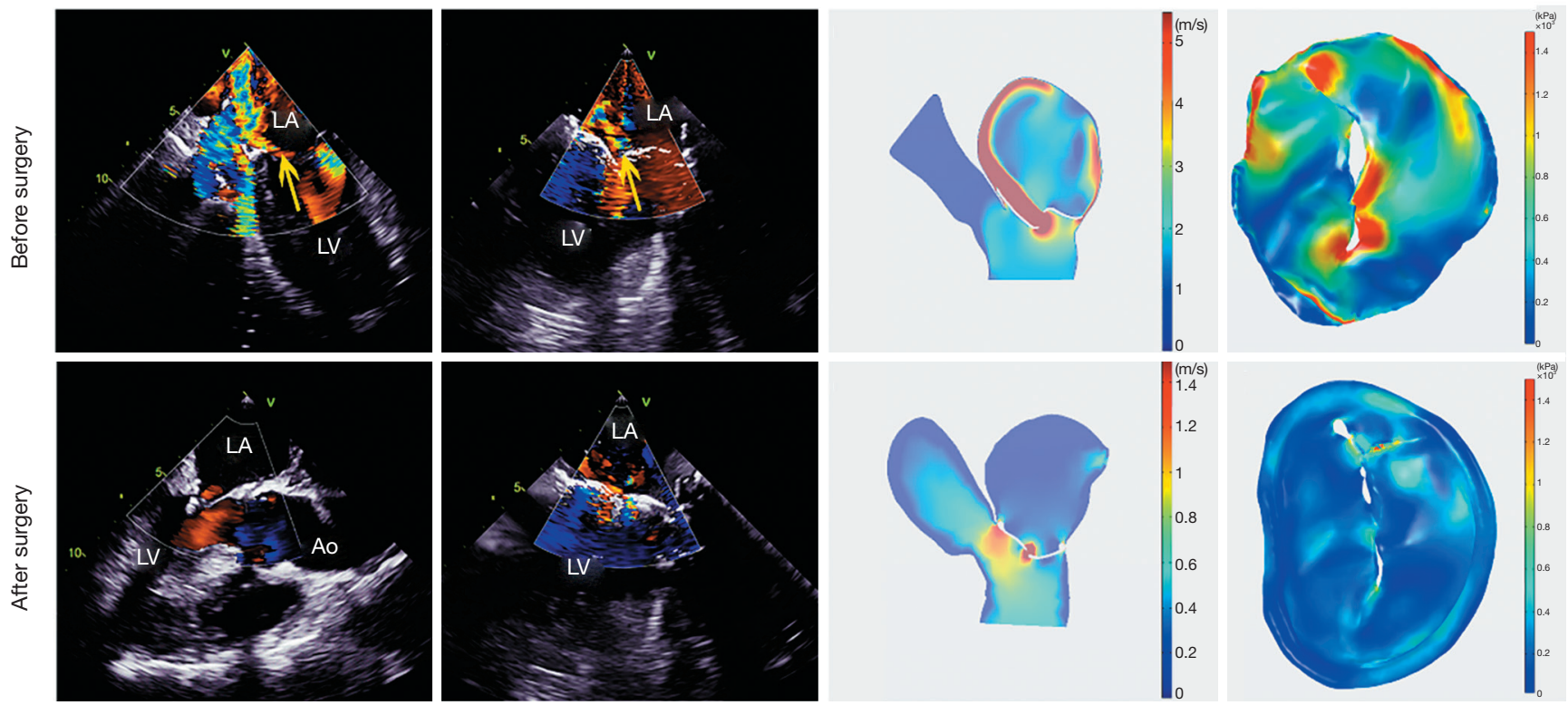

Figure 7 Accuracy of in vitro hemodynamics testing. The grade of regurgitation and the VCW measured in vitro and in vivo had high consistency, both before and after surgery. In addition, stress analysis in CFD showed that the mean stress on the mitral valve had reduced significantly from 1.18 to $0.59 \mathrm{MPa}$ after surgery. CFD, computational fluid dynamics; VCW, vena contracta width.

Table 4 Surgery simulation for 11 patients with severe prolapse

\begin{tabular}{|c|c|c|c|c|c|c|c|c|c|c|c|c|}
\hline \multirow{3}{*}{ Patient } & \multirow{3}{*}{$\begin{array}{l}\text { Leision } \\
\text { area }\end{array}$} & \multicolumn{6}{|c|}{ Before surgery } & \multicolumn{4}{|c|}{ After surgery } & \multirow{3}{*}{$\begin{array}{l}\text { Recommendation } \\
\text { - for repair }\end{array}$} \\
\hline & & \multicolumn{3}{|c|}{ Grade of regurgitation } & \multicolumn{3}{|c|}{ VCW (mm) } & \multicolumn{2}{|c|}{ Grade of regurgitation } & \multicolumn{2}{|c|}{ VCW (mm) } & \\
\hline & & In vivo & 3DP model & CFD & In vivo & 3DP model & CFD & 3DP model & CFD & 3DP model & CFD & \\
\hline Patient 1 & $\mathrm{P} 1, \mathrm{P} 2$ & 4 & 4 & 4 & 9.1 & 8.8 & 9.2 & 1 & 1 & 2.3 & 2.1 & - \\
\hline Patient 2 & P3 & 3 & 3 & 3 & 6.5 & 5.9 & 6.2 & Minor & Minor & 1.0 & 1.1 & $\sqrt{ }$ \\
\hline Patient 4 & $\mathrm{P} 2$ & 3 & 3 & 3 & 7.2 & 7.2 & 6.9 & Minor & Minor & 0.9 & 0.8 & $\sqrt{ }$ \\
\hline Patient 5 & P2, P3 & 4 & 4 & 4 & 8.8 & 8.2 & 8.6 & Minor to mild & $\begin{array}{l}\text { Minor to } \\
\text { mild }\end{array}$ & 1.6 & 1.4 & - \\
\hline Patient 6 & $\mathrm{P} 1, \mathrm{P} 2$ & 4 & 4 & 4 & 7.6 & 7.9 & 8.2 & 1 & 1 & 2.2 & 2.0 & - \\
\hline Patient 10 & $\mathrm{P} 2$ & 3 & 3 & 3 & 5.9 & 6.2 & 6.1 & Minor & Minor & 0.8 & 0.8 & $\sqrt{ }$ \\
\hline Patient 11 & $\mathrm{P} 1, \mathrm{P} 2$ & 4 & 4 & 4 & 6.3 & 5.8 & 6.4 & 1 & 1 & 1.9 & 2.1 & - \\
\hline
\end{tabular}


Table 5 Surgery simulation for patient with Barlow disease

\begin{tabular}{lcccc}
\hline Surgical plan & PML length $(\mathrm{mm})$ & Residual length of AML $(\mathrm{mm})$ & Pressure gradient $(\mathrm{mmHg})$ & LVOT obstruction \\
\hline Plan 1 & 14.0 & 2.8 & 6.8 & No \\
Plan 2 & 14.5 & 3.1 & 7.0 & No \\
Plan 3 & 15.0 & 3.2 & 8.4 & No \\
Plan 4 & 15.5 & 3.4 & 11.4 & No \\
Plan 5 & 16.0 & 3.8 & 14.1 & No \\
Plan 6 & 16.5 & 4.2 & 17.2 & Yes \\
Plan 7 & 17.0 & 4.5 & 17.3 & Yes \\
Plan 8 & 17.5 & 5.1 & 17.6 & Yes \\
Plan 9 & 18.0 & 5.4 & 17.8 & Yes \\
\hline
\end{tabular}

events. LV function is also well protected with the MV preserved. However, MVR is a complicated procedure with high technical requirements, and uncertainty in the surgical outcome and possible postoperative complications have limited its widespread application. About 3.5 million patients in China are now suffering from valvular heart disease, with MR accounting for a large proportion, according to the national cardiovascular disease report in 2018 (15). With the aging of China's population, there will be an increasing number of patients with MR attributable to valvular degeneration. Further efforts are needed to ensure more patients benefit from MVR and to reduce the adverse reactions caused by anticoagulant drugs.

Traditionally, medical image data, including CTA and 3D-TEE, are mainly used in the diagnosis of cardiovascular disease. In recent years, the development of 3DP technology and its application in the medical field have reduced the singular reliance on image analysis. 3DP cardiovascular models provide surgeons with impressive insights and better understanding of the location and size of lesions, which cannot be achieved with 2D images. However, previous studies were focused on forming rigid anatomical models made of hard polymers (16-21), whereas a 3DP dynamic model made of flexible silicone can offer more detailed information concerning hemodynamics. Although CFD has also been applied for mitral repair simulation in previous research, models of the left heart system are often simplified and derived from only one modality (e.g., MRI) (22). Furthermore, the simulation of possible complications after mitral repair and comparisons of 3DP dynamic models and CFD have not been discussed in the literature.

The objective of our study was to simulate the MV repair procedure using a 3DP dynamic model and CFD, hoping to address or provide a reference for certain clinical issues that have particularly troubled surgeons. First, in a retrospective cohort, we evaluated the accuracy of hemodynamic testing in our 3DP dynamic model and CFD by comparing the data obtained in vitro and in vivo. The grade of MR and the VCW measured in vitro and in vivo had high consistency, both before and after the surgical simulation, which proved that the 3DP dynamic model and CFD can be used to predict surgical outcomes. Next, we examined 11 cases of patients transferred to mitral replacement with severely prolapsed MVs. The results showed that 5 patients would have good outcomes after surgery while the other 6 were not recommended for mitral repair with mild or more residual MR.

Complications following MV repair, such as LVOT obstruction, are another consideration for surgeons in their selection of procedure. Risk factors for LVOT obstruction include a tall PML $(>1.5 \mathrm{~cm})$, a ratio of AML to PML length $>1.3$, distance between the IVS and coaptation point (LVOT height) $<2.5 \mathrm{~cm}$, increased basal IVS thickness $>1.5 \mathrm{~cm}$, and small LV cavity ( $\mathrm{LV}$ end-diastolic dimension $<4.5 \mathrm{~cm})(23,24)$. However, these standards are not absolute or applicable to every patient. In our study, we discussed 2 special cases of potential LVOT obstruction. One was a patient with $\mathrm{BD}$, the other had a small heart cavity. LVOT obstruction occurred when the PML length was $>16.5 \mathrm{~mm}$ in the BD patient, and when IVS thickness was $>12.0 \mathrm{~mm}$ in the patient with a small heart cavity. This demonstrated the great potential and advantages of 3DP modeling and CFD in individualized diagnosis and treatment.

A comparison of the $3 \mathrm{DP}$ model and CFD with traditional image data is given in Table 7 . The $3 \mathrm{D}$ material 
3D-TEE and model of MV
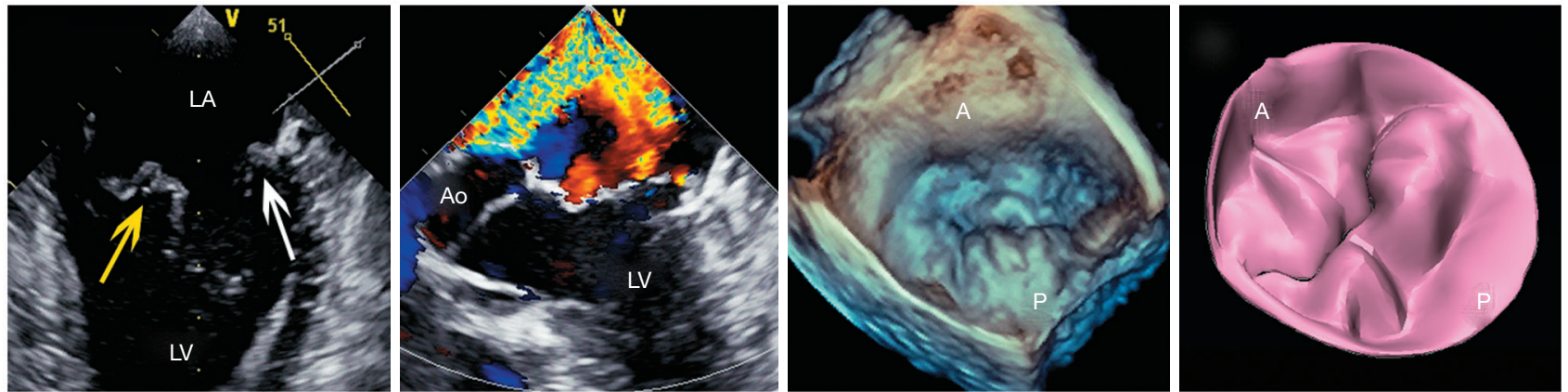

Surgery simulation
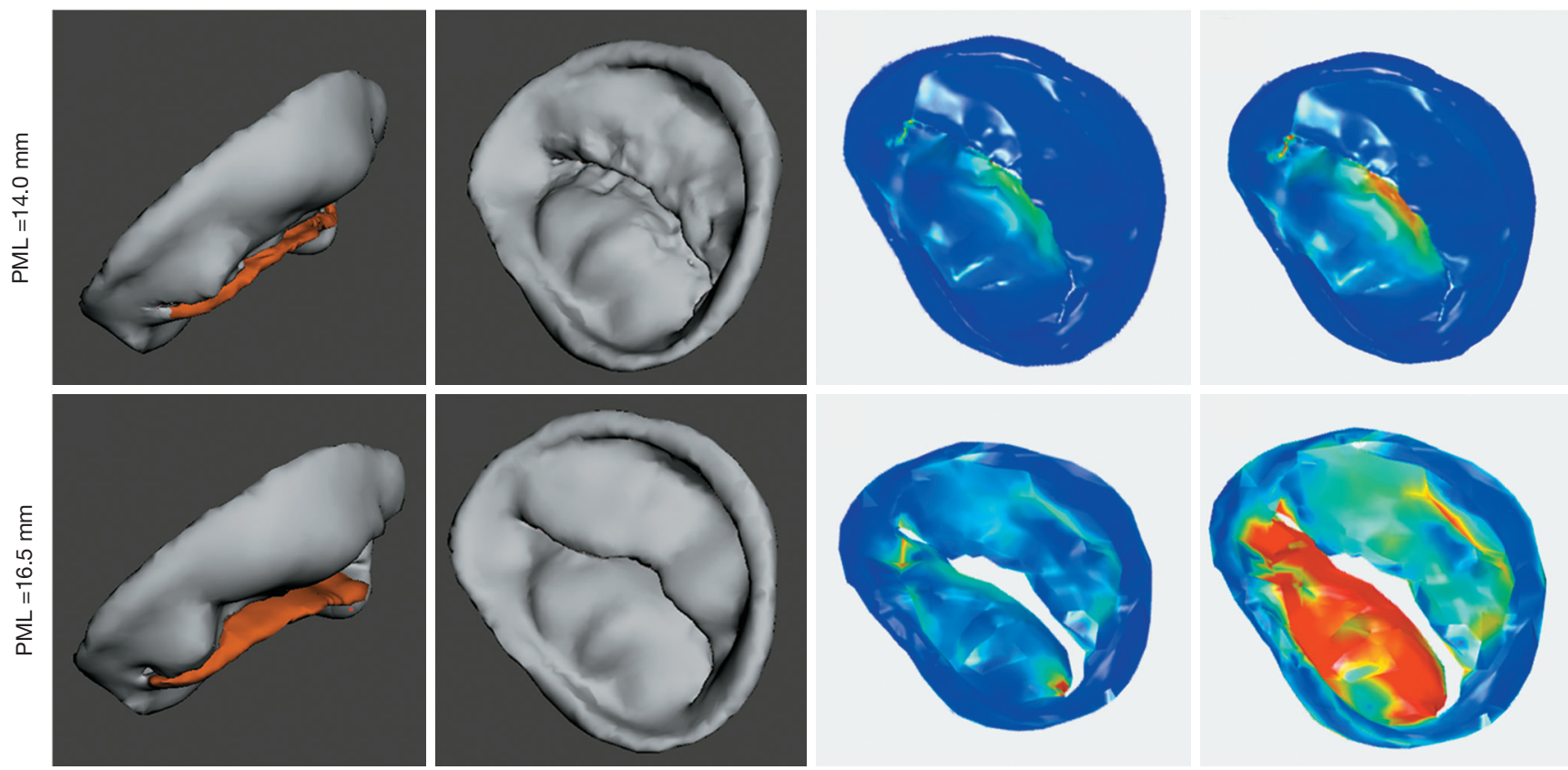

Figure 8 Surgical simulation of patient with Barlow disease, using different PML lengths from 14.0 to $19.0 \mathrm{~mm}$ (with a 0.5 -mm increase on each attempt). The results show that SAM as well as LVOT obstruction occurred when the PML length reached 16.5 mm, with a residual length of AML at $4.2 \mathrm{~mm}$. AML, anterior mitral leaflet; LVOT, left ventricular outlet; PML, posterior mitral leaflet; SAM, systolic anterior motion.

object demonstration, surgical simulation, preoperative hemodynamic testing, and possible complications are all factors that cannot be obtained from traditional image datasets. We compared the 3DP dynamic model and CFD for hemodynamic testing in vitro. The difference between the degree of MR and the VCW measured in both the model and CFD was not statistically significant. The main advantage of our 3DP dynamic model is the vivid morphological display it offers surgeons and its ability to mimic the texture of heart tissue. Younger or inexperienced doctors can be trained using our 3DP model, thus improving their surgical skills. However, CFD is more convenient to perform and can be used to obtain hemodynamic parameters of interest, such as the velocity and pressure gradient, at any point inside the heart.

We further studied a prospective cohort that was divided into a 3DP-guided group and a traditional image-guided group. The results showed that the rate of transfer from repair to replacement, along with surgery time, could be reduced with the aid of the $3 \mathrm{DP}$ dynamic model and CFD 
Table 6 Surgery simulation for patient with small left heart cavity

\begin{tabular}{lccc}
\hline Surgical plan & Basal interventricular septum thickness $(\mathrm{mm})$ & Pressure gradient $(\mathrm{mmHg})$ & LVOT obstruction \\
\hline Plan 1 & 14.0 & 17.0 & Yes \\
Plan 2 & 13.5 & 15.2 & Yes \\
Plan 3 & 13.0 & 14.7 & Yes \\
Plan 4 & 12.5 & 14.1 & Yes \\
Plan 5 & 12.0 & 10.2 & No \\
\hline
\end{tabular}

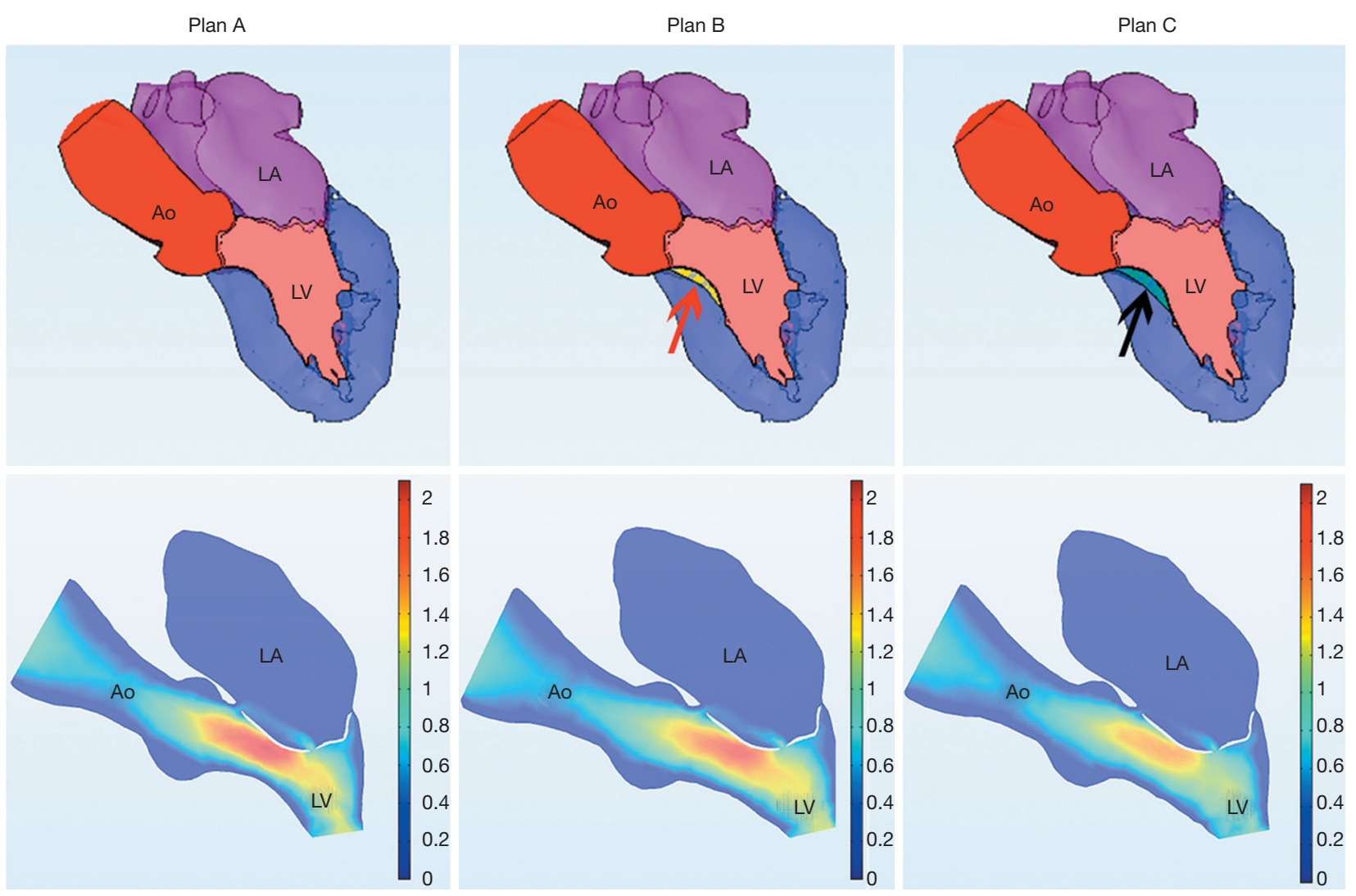

Figure 9 Surgical simulation of patient with small left heart cavity. Plan A was MVR without any intervention to the interventricular septum. Plan B was a $0.5-\mathrm{mm}$ decrease in interventricular septal thickness (red arrow) before mitral repair. Plan C was a 1.0-mm decrease in interventricular septal thickness (black arrow) before mitral repair. The result showed that the best surgical outcome occurred when the septal thickness was less than $12.0 \mathrm{~mm}$ (Plan C).

analysis before surgery. This validated the clinical value of our model and of CFD in improving the benefit to patients of MV repair with reduced surgery time.

Although more than $95 \%$ of primary MR cases can be successfully repaired in expert centers, repair rates vary widely depending on the experience of the center and the surgeons (25). Our 3DP dynamic model and CFD, despite being derived from 3D-TEE and CTA image data, can offer unique information on hemodynamics, surgical outcomes, and possible postoperative complications that are not available from traditional image datasets. Such information could provide essential guidance, especially for 
Table 7 Comparation of 3DP model and CFD with traditional image data in surgical value

\begin{tabular}{|c|c|c|c|c|c|c|c|c|}
\hline Data & $\begin{array}{l}\text { Cardiac } \\
\text { structure } \\
\text { assessment }\end{array}$ & $\begin{array}{l}\text { Surgery } \\
\text { simulation }\end{array}$ & $\begin{array}{c}\text { Hemodynamic } \\
\text { testing }\end{array}$ & $\begin{array}{l}\text { Prediction for } \\
\text { surgical effects }\end{array}$ & $\begin{array}{l}\text { Prediction } \\
\text { for possible } \\
\text { complication }\end{array}$ & Data obtained & Accuracy & Time cost \\
\hline 3DP model & $\begin{array}{l}\text { Three } \\
\text { dimensional; } \\
\text { stereo; } \\
\text { material object } \\
\text { demonstration }\end{array}$ & $\begin{array}{l}\text { Yes (physical } \\
\text { simulation, } \\
\text { offer good } \\
\text { opportunity for } \\
\text { young surgeons } \\
\text { to practice) }\end{array}$ & Yes & Yes & Yes & $\begin{array}{l}\text { Hemodynamic } \\
\text { change after surgery, } \\
\text { including velocity and } \\
\text { pressure gradient }\end{array}$ & $\begin{array}{c}\text { In good } \\
\text { consistency } \\
\text { with in vivo }\end{array}$ & $\begin{array}{l}\text { Long (about } \\
6 \text { hours for } \\
\text { one model) }\end{array}$ \\
\hline CFD & $\begin{array}{l}\text { Three } \\
\text { dimensional; } \\
\text { digital }\end{array}$ & $\begin{array}{l}\text { Yes (digital } \\
\text { simulation) }\end{array}$ & Yes & Yes & Yes & $\begin{array}{l}\text { Easy to obtain } \\
\text { any hemodynamic } \\
\text { parameter of interest } \\
\text { (velocity, pressure } \\
\text { gradient, stress, } \\
\text { streamline etc.) at any } \\
\text { point inside the heart }\end{array}$ & $\begin{array}{l}\text { In good } \\
\text { consistency } \\
\text { with in vivo }\end{array}$ & $\begin{array}{l}\text { Short and } \\
\text { convenient } \\
\text { (about } 1 \\
\text { hour for one } \\
\text { model) }\end{array}$ \\
\hline
\end{tabular}

Table 8 Comparation between 3DP-guided group and image-guided group in prospective cohort

\begin{tabular}{|c|c|c|c|}
\hline Clinical characteristics & 3DP-guided group & Image-guided group & $\mathrm{P}$ \\
\hline Male & $6 / 10$ & $5 / 10$ & 0.65 \\
\hline Mitral regurgitation before surgery & & & 0.62 \\
\hline Moderate & 2 & 1 & \\
\hline Severe & 5 & 4 & \\
\hline \multicolumn{4}{|l|}{ Surgery } \\
\hline Mitral repair & 3 & 6 & - \\
\hline Mitral replacement & 7 & 4 & - \\
\hline VCW after surgery(mm) & $1.10 \pm 0.31$ & $1.01 \pm 0.37$ & 0.56 \\
\hline Surgery time (h) & $4.70 \pm 0.31$ & $4.41 \pm 0.27$ & 0.04 \\
\hline
\end{tabular}

inexperienced surgeons, in surgical decision-making.

\section{Study limitations}

There are several limitations in our study to address. First, except for concerns about outcomes and complications, there are other difficult issues that surgeons have to overcome in mitral repair, such as reconstruction of chordae and papillary muscles. These procedures are not easy to simulate in vitro due to limits in the field of view of 3D-TEE and CTA imaging. In our study, 8 patients had rupture of chordae, which contributed to their transfer from MVR to replacement. This could not be simulated in vitro. Secondly, the rate of postoperative MR regurgitation increases linearly with time. It has been found 
that freedom from MR reduces to $82.2 \%$ at 5 years and to $64.9 \%$ at 10 years (26). Our study, although showing great potential in predicting the short-term effects of mitral repair, has limited value in predicting long-term outcomes and disease recurrence. Thirdly, the sample size was relatively small. We paid more attention to the methodology and feasibility of in vitro surgical simulation, demonstrating that $3 \mathrm{DP}$ and $\mathrm{CFD}$ are useful tools in surgical decision-making.

Finally, multiple factors are taken into consideration when surgeons are making surgical plans for a specific patient, including age, coexisting disorders, and medication use. Our study could only provide references concerning surgical outcomes and possible complications, but was not determinative.

\section{Conclusions}

We proved that a 3DP dynamic model and CFD could offer detailed outcome-relevant information for MR. For the prediction of surgical outcomes, the grade of MR and the VCW measured in vitro and in vivo had high consistency both before and after surgery. Furthermore, for challenging cases, 3DP with CFD has shown great potential in individualized surgical planning. Medical images are being transformed into powerful tools in the surgical treatment of cardiovascular diseases.

\section{Acknowledgments}

Funding: This study was funded by the National Natural Science Foundation of China (No. 81771849).

\section{Footnote}

Reporting Checklist: The authors have completed the MDAR reporting checklist. Available at http://dx.doi.org/10.21037/ atm-20-7960

Data Sharing Statement: Available at http://dx.doi. org/10.21037/atm-20-7960

Conflicts of Interest: All authors have completed the ICMJE uniform disclosure form (available at http://dx.doi. org/10.21037/atm-20-7960). The authors have no conflicts of interest to declare.

Ethical Statement: The authors are accountable for all aspects of the work in ensuring that questions related to the accuracy or integrity of any part of the work are appropriately investigated and resolved. The study was conducted in accordance with the Declaration of Helsinki (as revised in 2013). The study was approved by Clinical Research Ethics Committee of Renmin Hospital of Wuhan University (No. WDRY2018-K032) and informed consent was taken from all individual.

Open Access Statement: This is an Open Access article distributed in accordance with the Creative Commons Attribution-NonCommercial-NoDerivs 4.0 International License (CC BY-NC-ND 4.0), which permits the noncommercial replication and distribution of the article with the strict proviso that no changes or edits are made and the original work is properly cited (including links to both the formal publication through the relevant DOI and the license). See: https://creativecommons.org/licenses/by-nc-nd/4.0/.

\section{References}

1. Nishimura RA, Otto CM, Bonow RO, et al. 2017 AHA/ ACC Focused Update of the 2014 AHA/ACC Guideline for the Management of Patients With Valvular Heart Disease: A Report of the American College of Cardiology/ American Heart Association Task Force on Clinical Practice Guidelines. Circulation 2017;135:e1159-95.

2. Valgimigli M, Bueno H, Byrne RA, et al. 2017 ESC focused update on dual antiplatelet therapy in coronary artery disease developed in collaboration with EACTS: The Task Force for dual antiplatelet therapy in coronary artery disease of the European Society of Cardiology (ESC) and of the European Association for Cardio-Thoracic Surgery (EACTS). Eur Heart J 2018;39:213-60.

3. Gammie JS, O'Brien SM, Griffith BP, et al. Influence of hospital procedural volume on care process and mortality for patients undergoing elective surgery for mitral regurgitation. Circulation 2007;115:881-7.

4. Holzhey DM, Seeburger J, Misfeld M, et al. Learning minimally invasive mitral valve surgery: a cumulative sum sequential probability analysis of 3895 operations from a single high-volume center. Circulation 2013;128:483-91.

5. Manabe S, Kasegawa H, Fukui T, et al. Influence of left ventricular function on development of systolic anterior motion after mitral valve repair. J Thorac Cardiovasc Surg 2013;146:291-5.e1.

6. Mihaileanu S, Marino JP, Chauvaud S, et al. Left ventricular outflow obstruction after mitral valve repair (Carpentier's technique). Proposed mechanisms of disease. 
Circulation 1988;78:I78-84.

7. Crescenzi G, Landoni G, Zangrillo A, et al. Management and decision-making strategy for systolic anterior motion after mitral valve repair. J Thorac Cardiovasc Surg 2009;137:320-5.

8. Kuperstein R, Spiegelstein D, Rotem G, et al. Late clinical outcome of transient intraoperative systolic anterior motion post mitral valve repair. J Thorac Cardiovasc Surg 2015;149:471-6.

9. Varghese R, Itagaki S, Anyanwu AC, et al. Predicting systolic anterior motion after mitral valve reconstruction: using intraoperative transoesophageal echocardiography to identify those at greatest risk. Eur J Cardiothorac Surg 2014;45:132-7; discussion 137-8.

10. Maragiannis D, Jackson MS, Igo SR, et al. Replicating Patient-Specific Severe Aortic Valve Stenosis With Functional 3D Modeling. Circ Cardiovasc Imaging 2015;8:e003626.

11. Mashari A, Knio Z, Jeganathan J, et al. Hemodynamic Testing of Patient-Specific Mitral Valves Using a Pulse Duplicator: A Clinical Application of Three-Dimensional Printing. J Cardiothorac Vasc Anesth 2016;30:1278-85.

12. Yousefi M, Pourmehran O, Gorji-Bandpy M, et al. CFD simulation of aerosol delivery to a human lung via surface acoustic wave nebulization. Biomech Model Mechanobiol 2017;16:2035-50.

13. Barasch E, Gottdiener JS, Larsen EK, et al. Clinical significance of calcification of the fibrous skeleton of the heart and aortosclerosis in community dwelling elderly. The Cardiovascular Health Study (CHS). Am Heart J 2006;151:39-47.

14. Nishimura RA, Otto CM, Bonow RO, et al. 2017 AHA/ ACC Focused Update of the 2014 AHA/ACC Guideline for the Management of Patients With Valvular Heart Disease: A Report of the American College of Cardiology/ American Heart Association Task Force on Clinical Practice Guidelines. J Am Coll Cardiol 2017;70:252-89.

15. National Health Commission. Available online: http:// www.nhc.gov.cn/

16. He L, Cheng GS, Du YJ, et al. Feasibility of Device Closure for Multiple Atrial Septal Defects With an Inferior Sinus Venosus Defect: Procedural Planning Using Three-Dimensional Printed Models. Heart Lung Circ 2020;29:914-20.
17. Schmauss D, Haeberle S, Hagl C, et al. Threedimensional printing in cardiac surgery and interventional cardiology: a single-centre experience. Eur J Cardiothorac Surg 2015;47:1044-52.

18. Shearn AIU, Yeong M, Richard M, et al. Use of 3D Models in the Surgical Decision-Making Process in a Case of Double-Outlet Right Ventricle With Multiple Ventricular Septal Defects. Front Pediatr 2019;7:330.

19. Su W, Xiao Y, He S, et al. Three-dimensional printing models in congenital heart disease education for medical students: a controlled comparative study. BMC Med Educ 2018;18:178.

20. White SC, Sedler J, Jones TW, et al. Utility of threedimensional models in resident education on simple and complex intracardiac congenital heart defects. Congenit Heart Dis 2018;13:1045-9.

21. Zhu Y, Liu J, Wang L, et al. Preliminary study of the application of transthoracic echocardiography-guided three-dimensional printing for the assessment of structural heart disease. Echocardiography 2017;34:1903-8.

22. Morgan AE, Pantoja JL, Weinsaft J, et al. Finite Element Modeling of Mitral Valve Repair. J Biomech Eng 2016;138:021009.

23. Ibrahim M, Rao C, Ashrafian H, et al. Modern management of systolic anterior motion of the mitral valve. Eur J Cardiothorac Surg 2012;41:1260-70.

24. Maslow AD, Regan MM, Haering JM, et al. Echocardiographic predictors of left ventricular outflow tract obstruction and systolic anterior motion of the mitral valve after mitral valve reconstruction for myxomatous valve disease. J Am Coll Cardiol 1999;34:2096-104.

25. De Bonis M, Alfieri O, Dalrymple-Hay M, et al. Mitral Valve Repair in Degenerative Mitral Regurgitation: State of the Art. Prog Cardiovasc Dis 2017;60:386-93.

26. Flameng W, Meuris B, Herijgers P, et al. Durability of mitral valve repair in Barlow disease versus fibroelastic deficiency. J Thorac Cardiovasc Surg 2008;135:274-82.

Cite this article as: Wang $\mathrm{H}$, Song $\mathrm{H}$, Yang $\mathrm{Y}$, Wu Z, Hu R, Chen J, Guo J, Wang Y, Jia D, Cao S, Zhou Q, Guo R. Hemodynamic testing using three-dimensional printing and computational fluid dynamics preoperatively may provide more information in mitral repair than traditional image dataset. Ann Transl Med 2021;9(8):632. doi: 10.21037/atm-20-7960 